\title{
Keywords for Open Peer Review
}
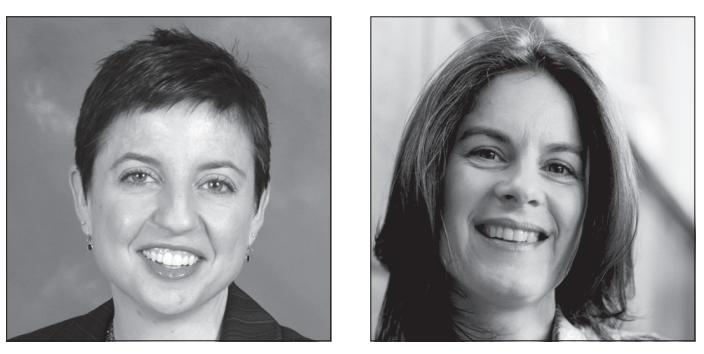

\section{Kathleen Fitzpatrick and Katherine Rowe}

Kathleen Fitzpatrick is Professor of Media Studies at Pomona College, in Claremont, California. She is author of The Anxiety of Obsolescence: The American Novel in the Age of Television, published in 2006 by Vanderbilt University Press, and of Planned Obsolescence: Publishing, Technology, and the Future of the Academy, forthcoming from NYU Press and available for open peer review online (http://mediacommons.futureofthebook.org/mcpress/plannedobsolescence). She is co-founder of the digital scholarly network MediaCommons (http://mediacommons.futureofthebook. org), and has published articles and notes in journals including the Journal of Electronic Publishing, PMLA, Contemporary Literature, and Cinema Journal.

E-mail: kfitzpatrick@pomona.edu
Chair and Professor of English, Bryn Mawr, Katherine Rowe teaches and writes about literature and media change. Trained as a scholar of Renaissance drama, she turned her attention to questions of the history of reading, writing and performance, from the Renaissance to the digital age after a period of intensive retraining in media studies. A recipient of grants from the NEH, the Mellon Foundation, and the PA Department of Education that support her work in media history, Prof. Rowe is a member of the editorial board of Shakespeare Quarterly and Associate Editor (responsible for the online edition) of The Cambridge World Shakespeare Encyclopedia (2011 publication date). Rowe currently serves on the Association of Departments of English Executive Committee and has contributed to several MLA initiatives.

E-mail: krowe@brynmawr.edu 
The past two years have seen a growing number of important experiments with peer review in the humanities. Scholars in diverse fields are recognizing both the opportunities afforded by new modes of scholarly communication online and our obligations to engage with them in a rigorous way. New approaches are being explored in a distributed way in local communities of scholars. Understanding what these transformations mean and the consequences for the way academics pursue research and share it is a project that cannot be tackled successfully in isolation. With several experiments now complete or ongoing, and others in the pipeline, humanities scholars could profit from some systems-level thinking about the common challenges and benefits that accrue to such experiments. ${ }^{1}$ As we begin to explore the connections between different experiments we can gain a clearer sense of patterns that emerge, understand them better, and apply this insight to other contexts for peer review. To do this in a productive way, we need a shared language and analytic framework for conversation across fields. This essay offers the beginnings of a shared vocabulary that could underpin such systems-level thinking, distilling keywords and key concepts from Shakespeare Quarterly's open peer review experiment in partnership with MediaCommons Press.

\section{Shakespeare Quarterly's open review experiment}

In the spring of 2010, Shakespeare Quarterly (SQ) designed and implemented a hybrid review process for its special issue 61:3 "Shakespeare and New Media," guest edited by Rowe. ${ }^{2}$ After researching different modes of digital publication and consulting the scholarship on peer review, the editors decided to test the opportunities and challenges offered by online open reviewing. ${ }^{3}$ For this experiment, the editors adapted SQ's established procedures to include a public and named phase of vetting, open to any reviewer but actively inviting those with relevant expertise. Running from 10 March to 5 May 2010, the process drew a self-selected community of Shakespeareans and others with expertise in media history.

This experiment is archived at MediaCommons Press, the open-scholarship venture that collaborated with the journal on this project. ${ }^{4}$ MediaCommons Press is a project of the digital scholarly network MediaCommons, which connects scholars in media studies and related fields, allowing them to experiment with new modes of open and collaborative publishing. MediaCommons Press is built on a multi-site installation of WordPress, a popular open-source blogging platform. It uses the CommentPress plugin, which was developed by

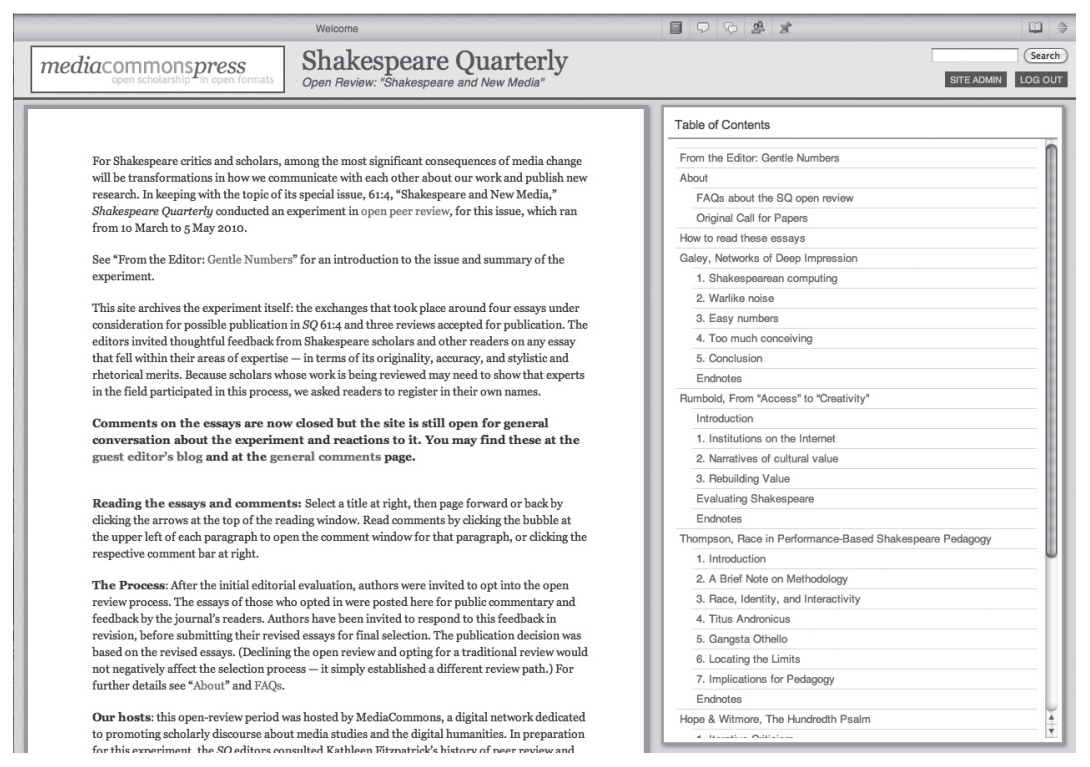

Figure 1. Screenshot of the MediaCommons Shakespeare Quarterly start page. 
the Institute for the Future of the Book in order to facilitate discussion of long-form texts at different levels of granularity, ranging from the paragraph to the page to the full document (see Figure 1).

Using these resources, forty-one participants (including the submitters and guest editor) posted more than 350 comments over 8 weeks, on four essays that had advanced to the stage of expert vetting (see "Workflow", below). The journal's open-review pages on MediaCommons were accessed over 9,500 times. Reviewers were asked to assess the essays according to the journal's usual criteria of "originality, accuracy, and stylistic and rhetorical merits." They were invited to make both paragraph-level comments and comprehensive assessments at the end of an essay. They themselves chose whether to include direct publication recommendations in their assessments; some did, others did not. Their comments ranged from passing responses to sustained engagement and challenge. Comments were not screened by the editors for content, though an initial screening was used to prevent spam. Authorial revisions in response to these comments were meticulous and, in two cases, very substantial. Publication decisions were made by SQ's editor, in consultation with the guest editor, on the basis of public exchanges on the MediaCommons site and authorial revision. The overall acceptance rate for this issue was 25\%: somewhat higher than the journal's overall acceptance rate of about $10 \%$, but appropriate for a special issue. The editorial process for 61:3 began with an open call for submissions; such solicitations will tend to draw a higher number of pertinent and appropriate submissions than a general submission pool.

For a traditional humanities journal, the review process the journal employed for this issue was novel in several respects. We subjected a set of essays to a public process of scholarly vetting in advance of publication decision. Other humanities journals have experimented in various ways with pre-publication commentary, but none to our knowledge have used that process as a means of vetting and a basis for a publication decision. The open review drew a critical mass of scholarly participants and reader responses of sufficient quality to support that decision. The New Media issue was also different from most other special issues at the journal, in reflecting interests of scholars and critics working in overlapping fields, as well as Shakespeareans involved in new media studies. This wider pool of expertise illuminated the interdisciplinary topic in ways that we had not anticipated. It allowed for kinds of accountability that are rarely possible in traditional peer review contexts: making patterns of reviewing visible, throwing the boundaries of knowledge of the field into clear relief, and surfacing methodological biases in a way that fruitfully challenged some of our basic assumptions.

These gains involved real trade-offs, however. The hybrid process we developed for SQ's experiment tested some but not all of the factors of concern to editors contemplating open review, and the process itself was labor-intensive, as we explain in more detail in the discussions below. We begin with framing ideas and close with some practical advice for journals interested in what this kind of project might look like.

\section{...one key to success in evolving practices of peer review is identifying processes suited to the publication and scholarly community in question.}

\section{A lexicon for open peer review}

Workflow: Any editorial board considering exploring new models of scholarly review should look closely at its own workflow and editorial values, and develop a process that reflects those in an organic way. Reading backwards through the scholarship on peer review, one gains a clear picture of how heterogeneous academic practices are from discipline to discipline and across venues - grant review panels, journal articles, and so on. All current peer review practices entail trade-offs between values we hold dear; none offers a gold standard for every context and field. Therefore, one key to success in evolving practices of peer review is identifying processes suited to the publication and scholarly community in question. Shakespeare Quarterly 
used two workflows in its initial trial of open peer review. The new process itself was a hybrid one; we identified the middle phase of the journal's traditional 3-stage process as the open phase. Thus all essays went through an initial editorial screening as usual at the journal. For those essays that advanced to the journal's second phase of review (expert vetting), authors were invited to opt into the new process but not required to participate.

Comparison of workflows for SQ 61:3

- Traditional workflow: editorial screening (closed) $\rightarrow$ expert vetting (invited, anonymous to reviewer and author) $\rightarrow$ editorial decision (closed)

- Hybrid workflow: editorial screening (closed) $\rightarrow$ expert vetting (opt-in, public, named) $\rightarrow$ editorial decision (closed)

Translation effects: When you set out to test an open or online component of your review process, you engage in a kind of "media translation." N. Katherine Hayles coins this phrase to describe the complex dynamics that emerge when traditional texts and textual practices migrate across media. ${ }^{5}$ Translating your procedures into a new environment will inevitably surface important, often unspoken, organizational and disciplinary values. Indeed, this effect is one of the chief benefits of pursuing such an experiment. Yet such unspoken values often surface in ways you cannot anticipate - they may catch you up or rebound unexpectedly.

For example, the editors of SQ were particularly concerned with developing a process that would be hospitable to untenured scholars. Early on, after consultation with junior colleagues and graduate students, we determined that reviewers would not be anonymous. We asked readers to register at the MediaCommons site using their own names, as our FAQs explained, so that untenured scholars whose work might be published in this way could show at reappointment that credentialed reviewers had participated. We wondered initially whether translating the expert vetting phase to an open forum would inhibit frankness: would reviewers feel they could be critical in public? That turned out to be less of a concern in practice than we expected (see "Accountability"). Yet paradoxically, the loss of anonymity that served to protect untenured authors later surfaced as an inhibiting factor for untenured reviewers. Unsurprisingly (in retrospect) few graduate students and junior faculty showed up to publicly critique essays and reviews by senior scholars. A key translation effect surfaced here, making visible the protective function that anonymity might provide junior scholars in an open forum - hitherto unrecognized precisely because junior scholars are rarely part of a traditional reviewing process. If the demographics of our reviewer participants is a fair indicator (largely established, tenured faculty in Shakespeare studies), a non-anonymous process may not be much more hospitable to junior faculty reviewers than a traditional one. Determining how to create sufficient safety for such untenured scholars without undermining the benefits of an open system presents a challenge for online review moving forward.

Openness: A concept important to computing, philosophies of management, governance, and systems theory, openness comprises several ideas in the context of peer review. In technical terms, it denotes an interactive platform with simple access procedures and limited access controls. In terms of reviewing process, it denotes an opt-in, public process. In the context of peer review, an open process may involve named or anonymous participants. For the many reasons discussed in this essay, SQ concluded that participants in our open vetting should be named (see "Translation effects", "Accountability" and "Peer-to-peer reviewing").

Peer-to-peer reviewing: Open review of the sort with which we have experimented is never wholly open; for obvious reasons, scholars are very concerned about anonymous internet trolls and the damage they can do. In order for this mode of review to work, it must take place in a community of trust, a community that has a shared, if constantly negotiated, set of standards both for the texts under review and for reviewer responsibilities. In any fully elaborated peer-to-peer review system, as Fitzpatrick has argued elsewhere, the most important element may well be the review of the reviewers, allowing the author, the editors, and the community to understand the context of comments left on the primary texts. ${ }^{6}$ Some of this context can be derived 
from community response, as an open reviewing system allows for a kind of back-and-forth among reviewers and between reviewers and authors that closed peer review does not provide. (See "Accountability" for a detailed example of how an exchange of this kind impacted SQ 61:3.) Some of this context will be built over time, as reviewers in a given community demonstrate their reliability and helpfulness within an online, public system the way they do in more traditional collective vetting environments, such as grant review panels. In a hybrid process, some of this context can be provided by the editors, who can curate a reviewing community by soliciting particularly thoughtful participants who will set communal standards. Understanding this larger task - evaluating not just the primary texts but the quality of the feedback they receive - will be crucial for authors as they contemplate revision and for editors as they make publication decisions (see "Role of the editor").

"Our-crowd" sourcing (credentialing): In an open or hybrid system, the "peer" part of peer-topeer review still matters; authors need to know that the reviewers with whom they are in dialogue are knowledgeable about the field. Given that this mode of review still bears the weight of its credentialing function, we need to be sure that the readers we would consider academic peers actively participate in the process. However, we would argue that confronting scholars' anxieties about the openness of the internet and acknowledging the benefit to be derived from shifting our understanding of the constitution of a "peer" from possession of the proper credentials to demonstration of expertise, interest and engagement would produce a more dynamic, and more publicly engaged mode of scholarly work. With an opt-in process focused on these qualifications, the boundaries of expertise that defines "our crowd" may be determined in a more distributed way - according to the intellectual commitments and networks of relationship that draw reviewers to the projects under review - than in a traditional process constituted by the editor alone. This can be particularly valuable when it comes to interdisciplinary topics, where expanding the disciplinary range of the reviewing community may provide for more rigorous vetting. But it also may change the role of the editor (see "Role of the editor").

A hybrid process can thus combine the strengths of "crowd sourcing" - outsourcing a large task to a broadly defined public through an open call for participation online - with those of our existing scholarly credentialing systems, producing what we might think of as "our-crowd sourcing."

Critical mass: Generating a sufficient crowd to produce a thorough review process requires strategic thinking, both about how to mobilize what may be a dedicated if small community of scholarly practitioners, as well as about how to draw reviewers from related fields to help ensure that the texts under review receive a critical mass of responses. In the case of SQ 61:3, we found an open review process was particularly suited to a special issue focused on an emergent set of scholarly practices. Those working in the intersection of new media and Shakespeare studies were eager to participate in shaping an issue that could have implications for the field's future and saw the experiment itself as an important contributor to knowledge. In advance of our open review SQ sought commitments to participate from scholars invested in the field; we set reasonable expectations, assuming that a portion of those who agreed in advance would not find it possible, practical, or comfortable to review this way, once they actually tried it. Word of mouth about SQ's experiment also drew in scholars and at least one practitioner from related fields.

Over-communication: Because so much less about the review process will be understood by everyone involved, over-communication becomes a crucial best-practice - and takes up a significant portion of an editor's labor. This includes providing detailed instructions for the use of the platform, available in multiple locations, and a prominently placed version of the usual instructions for reviewers, adapted to the platform being used. Briefings to reviewers in which they can explore the reviewing environment are helpful in establishing a clear understanding of review processes expectations and deadlines, readiness to collaborate in collective reviewing, and a familiarity with the technology. Many reviewers may be willing to participate but still experience 
technical challenges. Realistically, many scholars, pressed for time, will skim instructions or skip them entirely. So expect to field questions in an ongoing way, throughout the process. As answers evolve, these can be folded into an online list. The FAQs for SQ 61:3 were generated in this fashion.?

Affordances: In setting up any new digital publishing experiment, the editors must think carefully about the specific affordances provided by the platform in use, how those affordances might support or hinder the desired kinds of review, and how editors might work with reviewers to take advantage of the platform's strengths and ameliorate any deficiencies. We knew from prior experiments that CommentPress's paragraph-based commenting structure privileges discussion of local issues, at the potential expense of more holistic, synthetic commentary. With this in mind, we specifically instructed the reviewers to leave overall comments as well as local comments and we highlighted the space for those overall comments on each article. Future platforms will undoubtedly offer more sophisticated ways of tying comments to specific portions of a text, but for the time being, the limitations of current systems must be kept in mind.

Time-delimited: However much we value process in our work, and however much we want to revise that work until it is as good as it can be, scholars do have a strong need to bring their projects to closure, to declare them done and to move on. Moreover, journals require predictable and feasible production processes. As we discovered with the SQ experiment, for some participants the dynamic environment of an open review process can become exhausting, after a point. It seems there's always one more comment, one more idea, one more issue to which the author should respond. Thus the time-delimited function of our current journal production processes turns out to be as much an intellectual matter as a practical one. Declaring fixed periods for any open phase of review will prod reviewers to get their comments posted in a timely fashion, allow authors to finalize their work and move on, and editors to make a publication decision. Given the volume of reviewer comments that may accrue to a single essay, some period for author revisions strikes us as essential to an open process. For SQ 61:3, our open review phase lasted eight weeks. After that phase closed, we provided a short (two-week) window for author revisions before the final publication decision, which was based on the revised essays.

Ownership: The communications landscape for scholarly publishing is changing rapidly. Editors considering an experiment in hybrid review need to establish the potential rights-holders for articlesin-process submitted publicly to the journal - and for the reviewer comments, which constitute the crucial value-added in a journal's vetting and credentialing process. ${ }^{8}$ Despite the fact that scholarly journals are the primary source of such added value, as Wheeler observes, journals themselves "are increasingly excluded in the contest for rights"; instead, rights might be considered to belong to the journal publisher, "to the reading public (via open access), to the author, to the author's institution (via institutional repositories), or to the agency that provided grants to support development of the research."' Before the SQ experiment, the editors sought advice from the journal's publisher, Johns Hopkins University Press, to establish its policy on pre-publication posting. The MediaCommons pages include a credit to the publisher, pointing to the version of record in print and on Project Muse, as Johns Hopkins requests routinely for pre-publication repositories.

Persistence: A core principle of open review is the provision that the texts under review and reviewers' comments will remain available. Thus one of MediaCommons' key requests in partnering with SQ was that we archive the process. The journal's publisher, Johns Hopkins University Press, supported this idea. The editors also committed to an understanding that the authors whose essays were reviewed in this way would have the right to remove their material at a later date, if they so chose. Increasingly, we suspect humanists will become more tolerant of the notion of multiple versions existing side by side (as Shakespeareans would remind us that many of Shakespeare's plays themselves did, in the Renaissance). Yet a permanent record of imperfection may be challenging for participants 
to contemplate. Scholars place a high premium on polished work and tend to want to hide early problematic drafts. And they may wish to reserve work that has not been accepted for future publication elsewhere.

Archives of open review
have the potential to
redress one of the chief
failings of conventional
review: that it rests on
an enormous amount
of invisible labor that
academics have no
systematic way to credit.

That said, there are several important reasons to maintain a persistent record of the review process. Archives of open review have the potential to redress one of the chief failings of conventional review: that it rests on an enormous amount of invisible labor that academics have no systematic way to credit. The contributions that reviewers have made to the development of our ideas remain visible in an open review forum, in a way that allows us to point to particularly cogent interventions and credit reviewers themselves as contributors to knowledge. As importantly, a persistent record allows for disinterested vetting of the process itself, something that substantially benefits later endeavors and is especially necessary when multiple fields grapple with systemic change. While it is more common in the sciences to view a process as an artifact in this way - as something that can itself be tested, reviewed, is potentially reproducible, and can be validated by reproduction - humanists too can benefit greatly from this. SQ's experiment would not have been pursued without the modeling provided by the open review of Planned Obsolescence archived on MediaCommons. The persistence of SQ's review site in turn allows others to see what issues were addressed and not addressed by the design of this experiment, what did and did not work. Finally, it supports serious peer reviewing of the process itself by scholars inside and outside the field. SQ's open phase for 61:3 has now been peer reviewed in this way and will likely be again. ${ }^{10}$

Accountability: The combined dynamics of visibility, peer-to-peer scrutiny of vetting comments, and a critical mass of invested reviewers who respect each other can provide for a higher level of accountability to the field as a whole than a traditional review process. For reviewers, there are clear trade-offs in making our critical engagements visible. For some, the experience of reviewing with others "looking over your shoulder" is uncomfortable. For others, a respectful but critical public voice came more easily than they had expected. Yet for editors, the enhanced understanding of the contours of a field as a whole that can be gained from a small crowd of vetters can be enormously valuable. Not only can the vettings themselves be scrutinized in a collective process but larger patterns of reviewing become visible. In the SQ experiment, these effects allowed us to make connections that would otherwise have been buried, and brought a deeper understanding of the stakes for new methods of research.

To give just one example, opening up the review process illuminated in a new way a methodological bias that underlies our basic assumptions in Shakespeare studies about what counts as good textual data. A thread of debate developed in the interstices of the essays, concerning the suitability of an electronic text (the Moby Shakespeare) to scholarly analysis. Based on a flawed 19th century edition, the Moby text is generally regarded as an inferior source but one essay under review used it as the basis for large-scale statistical arguments about verbal patterns in Shakespeare's genres. Reviewers were quick to question the validity of analysis based on its source, but in the context of an open venue the authors were able to respond and did so trenchantly. They pointed out that their mode of analysis is not susceptible to local-level variation, since it aggregates larger patterns, and was not, therefore, invalidated by the choice of source text. Basic disciplinary practices were at stake in this conflict. The exchange illuminated a methodological bias underlying conventional wisdom about what makes a 
suitable text for study in this field - deepening the editors' understanding of what is at stake in new modes of reading enabled by digital tools. Indeed, the chief goal of this special issue - to advance our understanding of the changes digital media bring to Shakespeare studies - was materially advanced by this push and pull between authors and reviewers, and between reviewers themselves.

Role of the editor: The kind as well as the amount of editorial labor changes in an open review process. Designing and implementing a new workflow will entail substantial communication tasks (see "Over-communication"). The constitution of a crowd, even a small one, will be labor-intensive (see "Critical mass"). A larger field of vetters is likely to produce more disagreement among reviewers and more commentary for authors and editors to grapple with. In this context, the editor's role entails something more complex than what is required when processing two reader reports, since publication decisions may involve arbitrating between multiple competing reviews. This amplified editorial workload was feasible with a guest editor on board and well suited to a special issue at SQ. But it would not be sustainable as a normal and ongoing process at the journal. For journals managed by solo, volunteer editors with a full-time academic workload it may not be feasible.

Whenever familiar procedures with high stakes are altered, those overseeing that change bear a huge responsibility for curating a process respectful to all involved. A deep worry for many editors contemplating new modes of review online is that appropriate reviewing behavior can be maintained only through constant vigilance of the editor alone. Many of us know of blogs and online fora where deliberate or inadvertent skirmishes precipitate open hostilities. In the SQ experiment, commenting behavior was generally substantive and respectful, though often quite challenging to the arguments in question. The editors did not preapprove comments before posting (we did screen every reviewer's first comment to ensure it was generated by a real person). We did not seek to control reviewer behavior in part because a key goal of our experiment was to understand the kind of reviewing behaviors that result when editors give control of the discourse of assessment to a community of scholarly reviewers. Success factors for SQ's experiment included modeling by particularly judicious reviewers early in the open phase, peer-to-peer correction, and self-correction by participants (see "Peer-to-peer reviewing"). Yet until scholars have a better sense of the degree to which the results we saw in SQ's limited experiment were outliers, editors contemplating such experiments should expect to invest a great deal of time, energy and thought into how they will fulfill their responsibilities to curate respectful processes.

It requires a systems-level conversation about multiple reviewing experiments before scholars can understand how the behaviors of "our crowd" online differ from our behaviors at conferences, symposia, grant-panels and review boards - and what the consequences may be for individuals and for a field if some of our less-gracious behaviors migrate from traditional contexts into permanent, public archives.

Design practices: The same best practices that apply to any new media development project apply to the development of journal procedures involving new technology. Begin with your goals and core values, and choose the tools that support them, not the other way around. Research into the development of virtual organizations (of which an online reviewing community is a small-scale version constituted for a short time) underscores how crucial it is to include participants from all phases of the publication process in your discussions about a review experiment. ${ }^{11}$

Sustainability: Whatever workflows and processes we design for new forms of online review, we must take into consideration the amount of time and effort they require, both from editors and from reviewers. It is all too possible to imagine a scenario in which the number of texts awaiting online review exceeds the ability of actual reviewers to undertake their evaluation. And it is likewise possible to imagine that initial enthusiasm and commitment to a dedicated topic will fail to translate into ongoing participation by opt-in reviewers. Of course, these challenges also plague conventional reviewing. For any mode of open review to be made sustainable 
(as for its traditional predecessors) its design must include the factors that motivate members of the community to participate. For open reviewing, such motivating factors may include some form of "pay-to-play," in which authors earn the right to submit their work for review through their own reviewing efforts. ${ }^{12}$ Whatever the motivation, however, editors must bear in mind the necessity that the labor involved for all participants remains sustainable over time. (See "Role of the editor.")

These keywords do not exhaust the issues that editors of journals taking on emergent digital publishing practices will need to consider. We hope they illuminate the kinds of questions that arise as everyone in the publishing process - authors, reviewers, editors, and publishers alike - contends with the new dynamics and affordances of networked systems. The openness privileged by such new publishing systems can appear at times to work counter to the careful deliberation for which conventional publishing methods have provided. Yet in a carefully designed process, these two values can instead be mutually reinforcing. Moving our feedback mechanisms out into the public arena can encourage greater thoughtfulness, greater generosity, and greater helpfulness in our approaches to reviewing one another's work. Moreover, getting more voices than the standard two to three blind reviewers involved in the process can allow a greater range of perspectives to be brought to bear in vetting the scholarship of the future. Finally, when undertaken in a sustained way, that process can provide a greater degree of accountability to the standards and needs of a field as a whole.

\section{Endnotes}

1 Bonnie Wheeler surveys these efforts in "The Ontology of the Scholarly Journal and the Place of Peer Review." Journal of Scholarly Publishing 42:3, forthcoming April 2011.

2 Portions of this description of the process are condensed from Katherine Rowe. "From the Editor: Gentle Numbers." Shakespeare Quarterly 61:3 (Fall 2010), iii-viii.

3 See Harriet Zuckerman and Robert K. Merton, "Patterns of Evaluation in Science: Institutionalization, Structure and Functions of the Referee System" Minerva 9.1 (1971): 66-100; Steven Shapin, A Social History of Truth: Civility and Science in Seventeenth-Century England (Chicago: U of Chicago P, 1994). Michèle Lamont, How Professors Think: Inside the Curious World of Academic Judgment (Cambridge, MA: Harvard UP, 2009); Kathleen Fitzpatrick, Planned Obsolescence: Publishing, Technology, and the Future of the Academy. http://mediacommons.futureofthebook.org/mcpress/plannedobsolescence/one/the-reputation-economy/.

4 Shakespeare Quarterly Open Review. MediaCommons Press. http://mediacommons.futureofthebook.org/mcpress/ ShakespeareQuarterly_NewMedia/about/faqs-about-thesq-open-review/.

5 N. Katherine Hayles, My Mother Was a Computer: Digital Subjects and Literary Texts (Chicago: U of Chicago P, 2005), 89.
6 Kathleen Fitzpatrick, "The Reputation Economy." Planned Obsolescence. http://mediacommons.futureofthebook.org/ mcpress/plannedobsolescence/one/the-reputation-economy/.

7 FAQs, SQ Open Review: "Shakespeare and New Media." http://mediacommons.futureofthebook.org/mcpress/ ShakespeareQuarterly_NewMedia/about/faqs-about-thesq-open-review/.

8 Wheeler, forthcoming.

9 Wheeler, forthcoming.

10 Larry Cebula, “Peer Review 2.0?" Northwest History blog, Monday, September 12, 2010. http://northwesthistory. blogspot.com/2010/09/peer-review-20.html.

11 Cummings, J., Finholt, T., Foster, I., Kesselman, C. and Lawrence, K.. 2008. Beyond Being There: A Blueprint for Advancing the Design, Development, and Evaluation of Virtual Organizations, report from an NSF Workshop on Developing Virtual Organizations, 29. Available at: http:// www.ci.uchicago.edu/events/VirtOrg2008/VO_report.pdf.

12 Wheeler, forthcoming. 